\title{
Study of cases of rupture uterus in a tertiary institute and its maternal and perinatal outcome
}

\author{
Rupali A. Gaikwad ${ }^{1 *}$, Niranjan N. Chavan ${ }^{2}$
}

${ }^{1}$ Department of Obstetrics and Gynecology, GMCH Aurangabad, Maharashtra, India
${ }^{2}$ Department of Obstetrics and Gynecology, LTMGH Sion, Mumbai, Maharashtra, India

Received: 03 July 2017

Accepted: 29 July 2017

*Correspondence:

Dr. Rupali A. Gaikwad,

E-mail: drrupaligaikwad@gmail.com

Copyright: (C) the author(s), publisher and licensee Medip Academy. This is an open-access article distributed under the terms of the Creative Commons Attribution Non-Commercial License, which permits unrestricted non-commercial use, distribution, and reproduction in any medium, provided the original work is properly cited.

\begin{abstract}
Background: Uterine rupture is undoubtedly one of the most tragic events that can occur in a women's life and tragedy becomes more grim when she is young. In India, in advanced cities the incidence of rupture preceded by obstructed labour is decreasing, in rural parts where there is inadequate care, lack of communication and transport, home deliveries by untrained dais incidence of rupture uterus is still high. So, the study is to evaluate the etiological factors, incidence, management modalities and maternal and perinatal outcome.

Methods: A prospective cross-sectional study of 46 cases of rupture uterus and maternal and Perinatal outcome, in the department of Obstetrics and Gynecology in government tertiary reference center.

Results: Overall incidence of uterine rupture is 1 in 924. Out of 46 cases 07 (15.22\%) were booked, and 39 (84.78\%) were referred patients. The 20-30 years age group is the most vulnerable age group. Out of 44 rupture uterus during labor, $13(22.72 \%)$ were spontaneous of intact uterus and $31(70.45 \%)$ were in scarred uterus. Subtotal abdominal hysterectomy was commonest modality of treatment used (28 out of 46 cases), followed by suturing of tear. There were 5 maternal deaths out of 46 patients, giving maternal mortality rate of $13.51 \%$. Perinatal mortality rate still on higher side was $76.08 \%$.

Conclusions: Most cases of rupture uterus are preventable with good antenatal and intra-partum care. Our study shows that there has been a decline in the overall morbidity in cases of rupture uterus and so also the mortality rate (decreased from 24.3 to $13.51 \%$ ).
\end{abstract}

Keywords: Maternal mortality, Perinatal mortality, Rupture uterus

\section{INTRODUCTION}

Uterine rupture is undoubtedly one of the most tragic events that can occur in a women's life. The tragedy becomes more grim when she is young. In India, in advanced cities the incidence of rupture preceded by obstructed labour is decreasing, but in rural parts where there is inadequate care, lack of communication and transport, illiteracy, home deliveries by untrained dais incidence of rupture uterus is still high.so purpose of the study is to evaluate the etiological factors, incidence, management modalities and maternal and perinatal outcome. In India, it accounts for 5-10\% of all maternal deaths. Previous caesarean section is the major risk factor for rupture of uterus. ${ }^{1}$

Delee had said 'once cesarean section always a cesarean section' but according to Munrro Kerr the dictum has changed to 'once cesarean section always a hospital delivery' Trial of scar has helped to decrease the number of repeat cesarean section in the cases where there are no recurrent indications. 
The initial signs and symptoms of uterine rupture are typically nonspecific, which makes diagnosis difficult and sometimes delays definitive therapy. From the time of diagnosis to delivery, only 10-37 minutes are available before clinically significant fetal morbidity becomes inevitable. Fetal morbidity occurs as a result of catastrophic hemorrhage, fetal anoxia, or both. The inconsistent premonitory signs and the short time for instituting definitive therapeutic action make uterine rupture a fearful event. In modern obstetrics, ruptured uterus at once conjures up a vision of poorly managed labour. It must be admitted, however that uterine rupture in exceptional cases is unavoidable. Occasionally these ruptures are "silent" and occur despite adequate obstetric care.

Hysterectomy once an accepted mode of treatment for ruptured uterus does not find favour with modern obstetrics and more conservative methods have been suggested i.e. suturing with or without sterilization and elective caesarean section in next confinement.

Indeed, it is not an exaggeration to say that the incident of uterine rupture is an index of obstetric civilization of a country, these two factors being inversely proportional to each other.

\section{METHODS}

A prospective cross-sectional study of 46 cases of rupture uterus and maternal and Perinatal outcome

\section{Inclusion criteria}

- All patients registered and unregistered clinically suspected to have a rupture uterus, patients presented with varying degree of shock, abnormal uterine contour, absent FHS, bleeding per vagina, pain in abdomen, hematuria

- Patients with spontaneous labor in cases of scarred/unscarred uterus

- Patients with previous vaginal delivery

- Cases with previous transverse/vertical lower cesarean /upper segment cesarean section

- Cases of rupture of scarred uterus due to other operations like Myomectomy, hysterotomy, operations for correcting uterine anomalies.

On admission, initial resuscitative management was done. A detailed history regarding sociodemographic profile, probable aetiological factors was taken. Emergency investigations were sent and emergency laparotomy was done. Obstetrics Hysterectomy or suturing of ruptured scar was done depending upon condition of the patient, parity, presence or absence of infection etc.

Post operatively patient's vital parameters were monitored intensively. Broad spectrum antibiotics given and patients requiring assisted ventilatory support were shifted to surgical intensive care unit as and when required.

Previous aspects of rupture uterus i.e. incidence, etiology, type of rupture, site of rupture, modalities of treatment, maternal morbidity and mortality and Perinatal mortality were analyzed and assessed.

\section{Exclusion criteria}

- Cases with scar dehiscence.

- Cases of direct uterine trauma.

\section{RESULTS}

In present study (2008-10), there were 46 cases of uterine rupture out of 42,542 deliveries giving an incidence of 1 in 924 . Table $1,39(84.78 \%)$ cases of rupture uterus were emergency cases and least $7(15.22 \%)$ cases were booked. Most common age group vulnrable was between 21-30 yrs (76.53\%). Uterine rupture was maximum in parity II-IV (73.91\%).

44 cases of rupture uterus were seen during labor, of which $31(70.45 \%)$ were seen in scarred uterus (previous one or two or three cesarean section) patients and 13 $(22.72 \%)$ cases seen in unscarred uterus which are either due to traumatic/ spontaneous cause which include obstructed labor, malpresentation, grandmultiparity etc. only 2 seen in antepartum period of which 1 was previous 2 LSCS and the other was classical cesarean scar rupture.

$33(71.74 \%)$ of rupture uterus seen in previous cesarean section patients, of which $31(93.94 \%)$ rupture occurred during labor and 2 ruptures during antenatal period.

Most common cause was previous cesarean section with short interpregnancy interval seen in 23 (67.64\%) patients, in that maximum i.e., 16 cases $(47.05 \%)$ were seen in 6-12 months inter pregnacy interval. And second most common cause found to be Grandmultiparity seen in $9(19.56 \%)$ patients. $4(8.69 \%)$ cases of rupture uterus seen in obstructed labor. Other $4(8.69 \%)$ cases traumatic i.e. we're following forceps delivery.

Most common site of scar rupture was lower uterine segment $(80.43 \%)$. In lower segment, anterior wall rupture with extension to lateral wall more commonly seen.

Extension to bladder seen in 4 cases $(8.69 \%)$ and extension to cervix and vagina seen in 4 cases $(8.69 \%)$. Broad ligament hematoma seen in $10(21.73 \%)$ cases. Least common site was Fundal rupture seen in 2 (4.34\%) cases of previous LSCS. Subtotal hysterectomy was required in maximum $28(60.86 \%)$ no of patients. Total hysterectomy in 2 patients. Associated surgeries include internal iliac artery ligation and bladder repair. Internal iliac artery ligation required to control hemorrhage. 
Table 1: Incidence of uterine rupture.

\begin{tabular}{|c|c|c|c|}
\hline & & No. & $\%$ \\
\hline \multirow{2}{*}{ Nature of admission } & Referred & 39 & 84.78 \\
\hline & Registered & 7 & 15.22 \\
\hline \multirow{3}{*}{ Age wise distribution } & Less than $20 \mathrm{yrs}$ & 2 & 4.35 \\
\hline & Between 21-30yrs & 35 & 76.53 \\
\hline & Above $30 \mathrm{yrs}$ & 9 & 19.12 \\
\hline \multirow{3}{*}{ In relation to parity } & Para I & 2 & 4.34 \\
\hline & Para II-IV & 34 & 73.91 \\
\hline & Para $>$ IV & 10 & 21.73 \\
\hline \multirow{8}{*}{ Etiology } & Rupture during pregnancy & 2 & 4.35 \\
\hline & Spontaneous & 2 & 4.35 \\
\hline & Traumatic & 0 & 0 \\
\hline & Rupture during labour & 44 & 95.65 \\
\hline & Rupture of intact uterus & 13 & 22.72 \\
\hline & Spontaneous & 9 & 69.24 \\
\hline & Traumatic & 4 & 30.76 \\
\hline & Scar rupture & 31 & 70.45 \\
\hline \multirow{10}{*}{$\begin{array}{l}\text { Distribution of rupture site on } \\
\text { laparatomy }\end{array}$} & Fundus & 2 & 4.34 \\
\hline & Upper segment & 3 & 6.52 \\
\hline & Lower segment: & 37 & 80.43 \\
\hline & Anterior wall & 5 & 17.24 \\
\hline & Posterior wall & 4 & 13.79 \\
\hline & Broad ligament hematoma & 10 & 21.73 \\
\hline & Extension to cervix and vagina & 4 & 8.69 \\
\hline & Extension to lateral wall & 11 & 37.93 \\
\hline & Extension to bladder & 4 & 8.69 \\
\hline & Ureter involvement & 0 & 0 \\
\hline \multirow{9}{*}{ Scar rupture } & During pregnancy & 2 & 2.86 \\
\hline & Classical & 1 & 3.03 \\
\hline & Previous 1 LSCS & 0 & 0 \\
\hline & Previous 2 LSCS & 1 & 3.03 \\
\hline & During labour & 31 & 93.9 \\
\hline & Classical & 0 & 0 \\
\hline & Previous 1 LSCS & 28 & 90.32 \\
\hline & Previous 2 LSCS & 2 & 6.45 \\
\hline & Previous 3 LSCS & 1 & 2.94 \\
\hline \multirow{13}{*}{ Etiological factors } & Grandmultipara (parity >4) & 9 & 19.56 \\
\hline & Previous cesarean section- & 33 & 71.73 \\
\hline & Classical cesarean & 1 & \\
\hline & LSCS-(1 or 2 or 3$)$ & 32 & \\
\hline & Foeto-pelvic disproportion & 4 & 8.69 \\
\hline & Malpresentation- & 3 & 6.52 \\
\hline & Transverse & 2 & \\
\hline & Breech & 0 & \\
\hline & Face / brow & 1 & \\
\hline & Instrumental delivery- & 4 & 8.69 \\
\hline & Forceps & 4 & \\
\hline & Vacuum & 0 & \\
\hline & Short interpregnancy interval in previous cesarean section & 23 & 67.64 \\
\hline \multirow{5}{*}{$\begin{array}{l}\text { Short interpregnancy interval in } \\
\text { previous LSCS patients }\end{array}$} & $<6$ Months & 0 & 0 \\
\hline & 6-12 months & 16 & 47.05 \\
\hline & $12-18$ months & 7 & 20.58 \\
\hline & $18-24$ months & 6 & 17.64 \\
\hline & $>24$ months & 5 & 14.70 \\
\hline
\end{tabular}


5 out of 46 patients expired giving maternal mortality rate as $13.51 \%$. Out of 5, 2 deaths occurred due to septicemia and one patient of early hemorrhagic shock following spontaneous rupture could not be survived postoperatively.

\section{Table 2: Analysis of modalities of treatment.}

\begin{tabular}{|lll|}
\hline Modality of treatment & No. of cases & $\%$ \\
\hline Suturing of tear & 16 & 34.78 \\
\hline Subtotal hysterectomy & 28 & 60.86 \\
\hline Total hysterectomy & 2 & 4.34 \\
\hline Internal iliac artery ligation & 27 & 58.69 \\
\hline Repair of bladder tear & 5 & 10.86 \\
\hline
\end{tabular}

Table 3: Causes of maternal death.

\begin{tabular}{|lll|}
\hline Cause & No. of deaths & $\%$ \\
\hline Septicemia & 02 & 4.34 \\
\hline DIC & 01 & 2.17 \\
\hline Acute Renal Failure & 01 & 2.17 \\
\hline Hemorrhagic shock & 01 & 2.17 \\
\hline
\end{tabular}

The perinatal mortality was seen in $35(76.08 \%)$ cases. 11 babies survived, which include 3 forceps delivery, 4 rupture of lower segment scar in a case of previous one/ two LSCS detected early and other cases include grand multipara in whom rupture detected immediate postdelivery. One was pre-term twins with previous LSCS. In 35 patients, the fetal heart was already absent on admission.

Table 4: Perinatal outcome.

\begin{tabular}{|lll|}
\hline Fetal outcome & No. of cases & $\%$ \\
\hline Live birth & 11 & 23.91 \\
\hline Still Birth & 35 & 76.08 \\
\hline
\end{tabular}

\section{DISCUSSION}

In India about $80 \%$ of population lives in villages where there are problems of illiteracy poverty and lack of health care facilities. Because of lack of adequate antenatal care most of patients coming to us with a ruptured uterus, were unregistered.

Rupture uterus is a serious complication of pregnancy and labour. Its incidence has gradually declined over the years, in our study it was 1 in 924 deliveries $(0.11)$ which is comparable to an Indian study done by Gupta A $(0.17 \%){ }^{2}$ The majority ruptures were in $21-30$ years age group $(76.53 \%)$ and $19.12 \%$ rupture occurred in $31-40$ years age (Table 1). Out of 46 cases of uterine rupture, 39 i.e. $84.78 \%$ cases were emergency admissions who had either no ANC visit or very infrequent (less than 3 ANC visits, while least $7(15.22 \%)$ cases were booked cases, similar to the study done by Singh A $(92.5 \%){ }^{3}$ Which denotes increased incidence of rupture in areas where there is illiteracy, poverty, lack of health services and lack of transport and communication.
As regards to its etiology, obstructed labour due to cephalo-pelvic disproportion and malpresentations, continued to be a major causative factor even in the last few decades.

This increase in scar rupture is due to an increasing use of caesarean section in the last decade or so, in place of difficult vaginal delivery. Nagarkatti RS, Ambiye VR, Vaidya PR. 1991 shows the changing trends in the aetiology of rupture uterus. The incidence of traumatic vaginal delivery as a cause has considerably declined from 17.1 to $7.8 \%$ while that of previous caesarean scar rupture has doubled; from. 11.4 to $23.4 \% .^{4}$

Esposito et al, an interpregnancy interval between cesarean delivery and a subsequent pregnancy of $<6$ months was nearly 4 times as common among patients who had uterine rupture than in control subjects. ${ }^{5}$

Although better alternatives in terms of fetal outcome and decreased maternal morbidity, improved these caesarean sections should not be accompanied by an increase in the rate of scar rupture. In our study $71.73 \%$ of uterine rupture occurred in cases with previous cesarean section and our observation was similar to Sheikh B.N. ${ }^{6}$ The increase in incidence in scarred uterus in our study may be due to the fact that this is a tertiary care center in a rural setup. Risk of uterine rupture increases when these wounds are allowed unsupervised labour. This is a matter of great concern and emphasis should be focused on reducing the primary cesarean sections rate in rural areas by promoting the normal deliveries at institutional and hospital levels and there must be strict indication for first cesarean section.

Higher parity is another risk factor for uterine rupture particularly in spontaneous rupture and induction cases. In our study $10(21.73 \%)$ of the total cases were grand multipara and $73.91 \%$ were para 2 to 4 . Nazma bano sheikh et al $n=50$ had $50 \%$ para 2 to $4 .^{6}$

$44(95.65 \%)$ of rupture uterus were seen during labor, out of which $31(70.45 \%)$ were seen in scarred uterus (previous one/two/three cesarean section) patients. While $13(22.72 \%)$ cases were seen in unscarred uterus which was either due to traumatic/ spontaneous causes which included malpresentation, obstructed labor, grandmultiparity. And only 2 seen in antepartum period, 1 was previous 2 LSCS and other was classical cesarean section. This clearly indicates that incidence of scar rupture increasing due to an increasing use of caesarean section in the last decade or so, in place of difficult vaginal delivery. Out of scarred uterus $(n=33)$ cases of rupture uterus observed during labour in 31 cases $(93.94 \%)$ while $2(6.06 \%)$ patients 1 previous 2 LSCS and 1 classical cesarean section patient had scar rupture during antenatal period.

More than one factor was responsible in some cases, previous cesarean section with short interpregnancy 
interval was seen in $23(67.64 \%)$ of cases, Stamilio DM etal An interval less than 6 months was associated with increased risk of uterine rupture (adjusted odds ratio [aOR] 2.66, 95\% confidence interval [CI] 1.21-5.82), major morbidity (aOR $1.95,95 \%$ CI 1.04-3.65), and blood transfusion (aOR 3.14, 95\% CI 1.42-6.95). ${ }^{7}$ Most common site of rupture was lower uterine segment (37) and its extension most commonly on left lateral wall seen in 29 out of 46 cases, Similar observation was found in other studies. 73 and least common site was fundal rupture seen in 2 cases. Similar to the other studies the most common site of uterine rupture was lower uterine segment followed by left lateral uterine rupture. ${ }^{8}(n=46)$, It has been seen that subtotal hysterectomy was the commonest modality of treatment used in $28(60.86 \%)$ patients. Scar repair and Obstetric Hysterectomies were major treatment modalities used in all studies. ${ }^{8,9}$ Associated operative measures like ligation of anterior division of internal iliac artery, repair of associated bladder tear is to be done as and when required.

5 out of 46 patients expired giving maternal mortality rate of $13.51 \%$. For which septicemia was the commonest cause. Seema Dwivedi et al, had $11.43 \%$ Maternal deaths. ${ }^{10}$

The perinatal mortality was $76.08 \%$ (35 out of 46 cases). Out of 46 babies, 11 babies survived, 3 were forceps delivery, 4 were rupture of lower segment scar in a case of previous one/ two LSCS detected early and other cases include grand multipara in whom rupture detected immediate post-delivery. One was pre-term twins with previous LSCS. Out of 12 live babies 7 required NICU admission. In 34 patients, the fetal heart was already absent on admission.

Fetal mortality is less in cases having rupture to admission interval less/traumatic rupture. This high maternal and perinatal mortality in our study was probably due to late referrals and presentation of women at hospital in state of shock, due to poorly developed health care system, delay in transportation and lack of awareness. Regular antenatal care, early referral, utilization of family care services are the important factors in preventing uterine rupture leading to maternal and perinatal mortality.

\section{CONCLUSION}

Thus, in conclusion, most cases of rupture uterus are preventable with good Antenatal and intra-partum care, and proper identification of high-risk cases. A good Antenatal care, counselling about risk of Rupture and convincing the necessity to give follow up at 37 weeks, getting women indoor prior to onset of labour and delivering at well-equipped hospital is necessary.
Vigilance during labour, especially in vaginal birth after caesarean and thorough monitoring of foetal heart will detect earliest signs of impending rupture. Immediate and timely intervention can avoid problems. Think twice before first caesarean and don't hesitate in taking for caesarean in a previous caesarean at the earliest indication. Our study shows that there has been a decline in the overall morbidity in cases of rupture uterus and so also the mortality rate. But we yet have a long way to go to achieve targets comparable to the developed countries.

Funding: No funding sources

Conflict of interest: None declared

Ethical approval: Not required

\section{REFERENCES}

1. Smith JG, Mertz HI, Merrill DC. Identifying risk factors for uterine rupture. Clinic perinatol. 2008;35:85-99.

2. Gupta A, Nanda S. Uterine rupture in pregnancy: a five-year study. Arch Gynecol Obstet. 2011;28(3):437-41.

3. Abha S, Srivastava C. Uterine rupture still a harsh reality. J Obstetr Gynaecol Ind. 2015:65(3):158-61.

4. Nagarkatti RS, Ambiye VR, Vaidya PR. Rupture uterus: changing trends in etiology and management. J Postgrad Med. 1991;37:136.

5. Esposito MA, Menihan CA, Malee MP. Association of interpregnancy interval with uterine scar failure in labor: a case-control study. Am J Obstet Gynecol. 2000;183(5):1180-3.

6. Sheikh BN, Sheikh S, Sheikh F, Raisham. Medical channel: Uterine rupture an ongoing tragedy of motherhood. Medical Channel. 2013;19(4):24-8.

7. Stamilio DM. Short interpregnancy interval: risk of uterine rupture and complications of vaginal birth after cesarean delivery. Obstet Gynecol. 2007;110(5):1075-82.

8. Rizwan N, Abbasi RM, Uddin SF. Uterine rupture, frequency of cases and fetomaternal outcome. JPMA. 2011;61(4):322.

9. Malik HS. Frequency, predisposing factors and fetomaternal outcome in uterine rupture. J Coll Physicians Surg Pak. 2006;16:472-5.

10. Dwivedi S, Kumar A. Uterine rupture a retrospective analysis of referral cases at a tertiary care centre in Kanpur city. Internat J Reproduct Contracept Obstetr Gynecol. 2017;4(4):1148-52.

Cite this article as: Gaikwad RA, Chavan NN. Study of cases of rupture uterus in a tertiary institute and its maternal and perinatal outcome. Int J Reprod Contracept Obstet Gynecol 2017;6:4023-7. 